\title{
THE PREDICTIVE VALUE OF INVESTOR SENTIMENT INDEX ON THE VOLATILITY OF THE MALAYSIAN STOCK MARKET
}

\author{
Nathrah Yacob, Nurul Shahnaz Ahmad Mahdzan \& Hamzah Arof
}

\begin{abstract}
Motivated by evidence that excess volatility could not be explained by the present standard value efficient market models coupled with the irrational behavioural anomaly observed in the Malaysian stock market, this study aims to construct the investors' sentiment index. The measure is intended to test whether the excess volatility may be contributed by non-fundamental factors. The index includes five proxies: stock market turnover, the number of initial public offerings, IPO initial returns, advancer decliner's ratio, and the widely applied consumer sentiment index. Factor analysis is employed to identify the common underlying factors from the suggested proxies to construct a composite index. The results suggest that the index is a reliable tool that is able to predict the volatility of the Malaysian Kuala Lumpur Composite Index (KLCI). These findings may be applied by practitioners to assist in making investment strategies, and, in addition, to an alternative paradigm in the asset pricing model.
\end{abstract}

Keywords: Investor Sentiment, Stock Market Volatility, Behavioural Finance, Malaysian Stock Market

JEL Classification: E22, F30

\section{Introduction}

Knowledge concerning stock volatility is crucial for the stock market, as the effect carries an uncertainty that may hinder investment decisions. Being the leading indicator of the economy, the uncertainty of stock returns may affect the growth prospect of the economy (Harvey, 1989). If excess volatility is not controlled, it may lead to a crisis, which is likely to affect the economy on a larger scale. In the Malaysian stock market, the unexplained volatility during crisis was persistent. Angabini and Wasiuzzaman (2010) found that during the 2008 global financial crisis, the volatility increased by $24.5 \%$ than the normal period. The persistent excess volatility that cannot be explained by the standard efficient market model render the relevance of efficient market theory in asset pricing (Shiller, 1981, 1987, 1990). Additionally, as suggested by Jing Tao, Tan and Poh (1999), and supported by Heng, Azizan and Yeap (2012), Malaysian stock markets are inefficient in the weak form in that it is possible to exploit the stock prices and

Corresponding author: Nathrah Yacob is a Lecturer at Taylor's Business School, Taylor's University. Email: Nathrah.YacobMohdYacob@taylors.edu.my.

Nurul Shahnaz Ahmad Mahdzan is a Senior Lecturer at the Department of Finance and Banking, Faculty of Business and Accountancy, University Malaya. Email: n_shahnaz@um.edu.my

Hamzah Arof is a Professor at the Faculty of Engineering University of Malaya. Email: ahamzah@um.edu.my. 
make consistent abnormal profits. These factors, therefore, warrant the importance of examining the determinants of the stock market volatility, so that investors and regulators are prepared with appropriate strategies and policies to protect against any negative impact on the economy.

However, the evidence of macroeconomic fundamentals as drivers to the volatile market has been inconclusive as different researchers reported different findings and impacts of economic variables in different countries. ${ }^{2}$ For instance, while Schwert (1989) found the effect of inflation and money growth to be weak for the US market volatility, Beltratti and Morana (2006) found that the interest rate and money growth affected the S\&P 500 volatility. On a larger sample, Davis and Keaton (2003) found a marginal effect of inflation in 13 developed and developing countries. In the Malaysian stock market, only the weakly interest rate affected the stock market volatility as reported by Zakaria and Shamsuddin (2012). These inconclusive findings motivated researchers to divert their attention from fundamental drivers to the non-fundamental drivers in explaining the volatile stock market.

Recent research literature seems to rely on empirical findings to verify the behaviour of stock prices in the local stock market where researchers have diverted their attention towards the evidence of psychological factors. A model of investor sentiment developed by Barberis, Shleifer and Vishny (1998) defined investor sentiment as the investor's under-reaction and overreaction behaviour to bad and good news regarding stock prices. Supported by the overreaction behaviours observed in the Malaysian stock market by Ali, Md Nassir, Hassan, and Abidin (2009, 2010), Angabini and Wasiuzzaman (2011) concluded that the volatility of Malaysian stocks was intense during the 2008 crisis period regardless of its sound economic fundamental. ${ }^{3}$ Coupled with the theory of excess volatility that proposes that people act inappropriately to the information received in the stock market (Shiller, 1989), investor sentiments connect in many ways that affect the stock price fluctuations.

The area of behavioural finance in Asia is still scarcely studied as it has only been recently accepted by the community of finance as a feasible paradigm to explain the decisions made by financial market participants that will eventually affect asset pricing. The evidence of psychological bias has emerged as an important factor influencing investment decisions in Asia, since it has been argued that a collective-oriented society is one of the factors that lead to behavioural bias. This notion is supported by Kim and Nofsinger (2008) who examined the socially collective behaviours of Asian communities and cultures. These factors justify the Malaysian stock market as a worthy example to observe the significance of investor sentiment in Asian countries. This is partly contributed by its culture and the absence of market makers in the market system. As an order-driven market or auction market in which prices are determined by solely the publication of orders

\footnotetext{
${ }^{2}$ Beltratti and Morana, 2002; Diebold and Yilmaz, 2008; Engle, Ghysels and Sohn, 2013; Rahman, Sidek and Tafri, 2009

${ }^{3}$ Malaysia experienced steady GDP growth of 5.8\% and 6.5\% during the year 2006 and 2007 consecutively with increasing industrial production index of $4.8 \%$ and $2.3 \%$ consecutively during the year 2006 and 2007 .
} 
to buy or sell shares, the movement of stock prices is transparent to the sentiment of stock market participants.

The measurement of investor sentiment remains controversial. For instance, among many others, Neal and Wheatley (1998) documented the predictive power of three well-known measures of individual investor sentiment: (1) the ratio of odd lot sales to purchases, (2) the level of discounts on closed-end funds, and (3) the net mutual fund redemptions on size premium predictions. Brown (1999), Lee et al. (1991), Neal and Wheatley (1998), and Swaminathan (1996) further extended that the volatility of closed-end investment funds was associated with the unusual level of individual investor's sentiment. The most recent study, by Baker et al. (2012), supported the use of indirect proxies to represent sentiment, for instance, closed end fund discount, market turnover and initial public offers' data. This measure is both relevant and practical. Their approach is analogous to the economists who treated surveys with some degree of suspicion due to the probability of potential gaps between how people actually act and how they react to a survey (Baker and Wurgler, 2006). Until now, no unanimous measure has been agreed upon. Therefore, the essence of investment strategy in which this paper suggested is to highlight the possibility that the measures of investor sentiment are relevant to the Malaysian stock market. In doing so, the first objective of this paper is to construct a reliable and applicable measurement of investor sentiment relevant to the Malaysian stock market. The second objective leads to the investigation as to whether investor sentiment could significantly predict the volatility of the stock market. This paper commences with a review of the literature (Section 2), the methodology (Section 3), analysis and discussion (Section 4), and, finally, the conclusion (Section 5).

\section{Literature Review}

\subsection{Stock market volatility}

The determinants of stock market volatility have been of significant interest to researchers in the past few decades. One of the motivations is to test the efficient market hypothesis, which was initially supported by Kraft and Kraft (1977). Another motivation is to examine the validity of the multi-factors model, which explains the pricing of stock returns by the movement of macroeconomic fundamentals. These findings shed light on the level of informational efficiency among markets in developed or developing countries. The research interest has thus turned towards an alternative paradigm to explain stock market volatility with more researchers starting to explore the possibility of non-fundamental variables, particularly, investor sentiment (Baker, Wurgler and Yuan, 2012; Brown and Cliff, 2005).

\subsection{Investor Sentiment}

The research interest on excess volatility started as early as the 1980s with the discovery of the earliest anomaly in the stock market (Shiller, 1987). There is, in fact, an abundance of discussion on the inconsistencies of the efficient market 
model for the aggregate stock market. To stock market observers, the anomalies imply that changes in prices occur for no fundamental reason at all; instead, they occur as a result of situations coined as animal spirit, sunspot, or simply, mass psychology. Lee, Jiang, and Indro (2002), and Verma and Verma (2007), while attempting to associate the relationship between investor sentiment and volatility, observed that noise traders who act collectively on non-fundamental signals might introduce a priced systematic risk. DeLong, Shleifer, Summers and Waldmann (1990) suggested that price deviations from fundamental values resulted from the uncertainty of investor sentiment. Arbitrageurs betting against mispricing would run the risk in the short term, and tend to drive investor sentiment to a larger extreme, thereby causing prices to deviate even further from fundamental values. The potential for loss and arbitrageurs' risk aversion reduces the size of the positions they are willing to take. This further deters the arbitrageurs from completely eliminating mispricing, and, as a result, investor sentiment prevails as a significant factor affecting security prices in equilibrium.

The studies by Lee et al. (2002), and Verma and Verma (2007) showed significant consistencies in the findings, where they observed negative effects between investor sentiment and stock return volatility, and a positive relationship between sentiment and stock market returns. Based on these findings, they concluded that sentiment is a priced risk factor that should always be taken into account when making investment decisions. These findings thus validate the theory of the involvement of noise trader sentiment in influencing stock market volatility, and underpin the high-volatility behaviour in stock markets.

Albeit due to the lack of a unanimously accepted definition of investor sentiment, new models have been progressively developed to measure the concept and have been applied to test the predictability in future returns of stocks held by investors. For instance, Neal and Wheatley (1998) documented the forecasting power of three popular investor sentiment measures: (1) the level of discounts on closed-end funds, (2) the ratio of odd lot sales to purchases, and (3) net mutual fund redemptions on the size premium predictions. Other researchers, e.g. Brown, (1999); Lee, Shleifer, and Thaler, (1991) further extended that the investor sentiment is associated with greater volatility of closed-end investment funds. A more recent study by Baker, Wurgler, and Yuan, (2012) supported the use of a number of indirect proxies to represent sentiment, such as closed end fund discount, market turnovers, and initial public offers' data, which were constructed into a composite index. The measure by Baker et al. (2012) is generally viewed as the most relevant and practical as they included all the other proxies adopted in previous studies (Baker and Stein, 2004; Baker and Wurgler, 2006; Baker and Wurgler, 2007). Baker et al. (2012) developed a composite index consisting of indirect measures of investor sentiment for six major stock markets. They suggested that there is no perfect index of investor sentiment, but, instead, there are a number of available, imperfect sentiment proxies that contain certain aspects of investor sentiment. The results of Baker et al. (2012) are consistent with the theoretical predictions of other researchers who proposed the direct measurement of investor sentiment derived from surveys and newsletters. Through robust 
checks, the composite index constructed by Baker et al. (2012) has been validated as a reliable representative of investors' sentiment. However, the effectiveness of the proxies is still not definitive and is subject to debate. Therefore, in this study, we include five available proxies to form a composite index based on a common component of the underlying factors. In accordance with Baker and Wurgler, (2007), a composite index from the available proxies is determined by Factor Analysis extracted by Principal Component Analysis (PCA).

\section{Methodology}

\subsection{Stock market volatility data and measurement}

To construct the volatility of the Malaysian stock market, we extracted the historical prices of the major Malaysian stock market indicator, the Kuala Lumpur Composite Index (KLCI) from 2000 to 2012. The KLCI was adopted as it represents Bursa Malaysia's (Malaysian stock market exchange) stock market performance. It is the main index that captures the interests of investors worldwide, representing the health of stock prices as well as the performance of investment portfolios. In this respect, the KLCI may also determine the direction of investor sentiment towards the current and future performance of the Malaysian stock market.

KLCI returns are computed from the monthly fluctuations of KLCI prices as per equation (1):

$$
R_{i}=\operatorname{Ln}\left(\frac{P_{t}}{P_{t-1}}\right)
$$

Where $P_{t}$ is the price of $K L C I$ on period $t, P_{t-1}$ is the offer price at $t-1$.

In line with the objective of this paper, we modelled the volatility of KLCI using the French, Schwert, and Stambaugh (1987) measure, estimated as the square root of the sum of squared daily returns, plus twice the sum of adjacent returns. The formula is as follows:

$$
\mathbf{O}_{m, t 2}=\sqrt{\sum_{i=1}^{N t} r_{i, t 2}^{2}+2 \sum \sum_{i=1} r_{i, t} r_{i, t+1}}
$$

Where $N_{t}$ is the daily returns of $r_{i, t}$ during the month $\mathrm{t}$ and $r_{\mathrm{i}, t+1}$ is the returns during the month $t+1$.

This estimator has three advantages over the rolling 12-month standard deviation method introduced by Officer (1973) and Merton (1980). The first advantage is that the accuracy of the standard deviation estimate is increased by sampling the return process more frequently. Secondly, a more precise estimation is obtained by using the returns of a particular month. Finally, this estimation uses 
a non-overlapping sample of returns, highlighting the variation in estimated volatility. This measure is more suitable for the monthly frequency data compared to the ARCH family as the clustering of variances is usually subtle and insignificant. This is consistent with the existence of the ARCH effect on monthly data observed by Brailsford and Faff (1996) in their attempt to model the volatility of the Australian stock market data. Their evidence suggested that the significance of ARCH and GARCH effects may be positively correlated with the frequency of data. Therefore, it may show minimal significance in the monthly data if the ARCH family is applied in this study.

\subsection{Investor sentiment proxies}

The first proxy of investor sentiment is the widely-known market turnover (TURN) (Baker and Stein, 2004 and Baker and Wurgler, 2007). The idea of including stock market turnover as one of the proxies in the sentiment index stems from Baker and Stein's (2004) method of measuring liquidity. The researchers suggested that liquidity could serve as a sentiment index. This is illustrated in a market with short sales constraints, where highly optimistic irrational investors participate to add liquidity, and, therefore, lead to the symptoms of market overvaluation. The authors briefly discussed the correlation of stock market turnover with direct surveys available in the US. However, information about the nexus between market turnover and stock market volatility is scarce. It is thus crucial to test the effect of liquidity proxies on the volatility of the Malaysian stock market in order to observe any new evidence of this. This measurement is shown in equation 3 :

$$
\text { TURN }=\frac{\text { monthly trading volume }}{\text { average shares listed }}
$$

The second proxy is the number of monthly initial public offerings (NIPO), measured as the log of the total number of IPO for the particular month during the sample period. Past studies have found that fluctuations of NIPO are caused by the euphoria of investor sentiment or behaviour towards the stock market or current economy (Derrien, 2005; Dorn, 2009; Lowry, 2003; Ritter and Welch, 2002; Yung, Colak and Wang, 2008).

The third proxy is the initial returns of Initial Public Offerings (RIPO), which represents the average initial first-day return on a particular month's offerings. $\mathrm{RIPO}$ is computed as the closing price of the first day less the offer price (Aggarwal, Leal and Hernandez, 1993, and Chan, Frankel and Kothari, 2004) and is equally weighted across the board, as given in equation 4 :

$$
R I P O=\left(\frac{P_{i 1}-P_{i 0}}{P_{i 0}}\right)
$$

Where, $P_{i 1}$ is the first-day closing price, and ${ }^{P_{i 0}}$ is the offer price. 
The fourth proxy of investor sentiment is the monthly frequency of the cumulative advancers and decliners stocks (ADV) (Brown and Cliff, 2005). The data are truncated at zero as the numerator and denominator of these variables have the tendency to move in the opposite direction. Data are extracted from Bursa Malaysia, and daily data are converted to monthly frequencies to be consistent with other proxies. This is shown in equation 5.

$$
A D V_{t}=\frac{\text { Number of advancers }_{\mathrm{t}}}{\text { Number of decliners }}
$$

Additionally, the final proxy of investor sentiment includes the widelyadopted consumer sentiment index that measures household perceptions of the general economy. The consumer sentiment index is published by the Malaysian Institute of Economic Research (MIER). As the index is currently available on a quarterly basis, it is interpolated into monthly intervals using the cubic spline method to maintain consistency with other variables. We apply a method that is popular among economists concerning the inconsistent frequency of financial data - cubic spline interpolation. This interpolation method estimates the values with a mathematical function, which has the advantage of minimising the overall surface curvature, resulting in a smooth surface that passes exactly through the input points. The proxies we selected are measured in different units and are generally not additive. Hence, it is necessary to convert each of them into comparable units so that the initial scale chosen for measuring them does not affect the results. In doing so, we standardised each series to have zero means and unit variances. This is obtained by subtracting the mean from each data and dividing each of them by the standard deviation.

To achieve the first objective of this study requires information regarding the macroeconomic conditions in Malaysia. Macroeconomic variables consist of the base lending rate (BLR) to represent the interest rate, consumer price index (CPI) to represent the inflation rate, and the effective exchange rate (EER) provided by the Bank for International Settlements (BIS) to represent the exchange rate. Finally, the industrial production index (IPI) and the broad money supply (M3) represent the real output and money in circulation. In order to promote consistency throughout the sample period, all the variables are extracted in monthly frequency from the beginning of the new millennium until 2012.

The crucial step in this paper is to construct a reliable and applicable measurement of investor sentiment relevant to the Malaysian stock market. In doing so, the identification of initial factors is determined by factor analysis with the Principal Component Analysis (PCA) extraction based on total variation in the data. Consistent with Baker and Wurgler (2006), the first-stage index (FSI) is formed from variables and their designated lags, where FSI is the first principal component (PC1), calculated from the weighted linear combination of variables, which accounts for the largest amount of total variation in the data. An issue to address here is the decision on the relative timing of the variables that reflect a 
given shift in sentiment earlier than other variables (Brown and Cliff, 2004; 2005). Some variables may reflect the same shift in sentiment before others. In general, proxies that involve firm supply decisions are further down the chain of events, and are likely to lag behind proxies based directly on the investor trading pattern on prices. The first step is to estimate the first principal components of the five proxies and their lags, thereby creating a first stage index with 10 loadings, one for each of the current and lagged proxies. This means that FSI is the linear combination of the proxies:

$$
\begin{aligned}
& F S I=W_{1} T_{U R N_{t}}+W_{2} T_{U R N_{t-1}}+W_{3} N I P O_{t}+W_{4} N I P O_{t-1}+W_{5} R I P O_{t}+W_{6} R I P O_{t-} \\
& +W_{7} A D V_{t}+W_{8} A D V_{t-1}+W_{9} C S I_{t}+W_{10} C S I_{t-1}
\end{aligned}
$$

Whereby, the weights $(\mathrm{W} n)$ are chosen to maximise the quantity of variance. A critical measure to obtain a pure measure of investor sentiment that is consistent with its definition is constructed. The proxy must be free from the influence of macroeconomic fundamentals. In achieving this, we regress each proxy with macroeconomic variables (BLR, CPI, IPI, EER and M3) in order to obtain a cleaner measure of investor sentiment, as demonstrated by Baker and Wurgler (2006). As the macroeconomic variables and proxies consist of data with residuals of different order integration, Pesaran and Shin (1997) suggested that the relationships between variables should be measured by the ARDL bound test model. The residuals, also known as noise factor from the model, are adopted as the cleaner proxy. The ARDL model with bound test is by far the closest parsimonious method to model the relationship between macroeconomic fundamentals and the proxies that comprise variables with a different integrated order.

The ARDL (p,q) model is adopted to implement this process as it has a number of advantages over VAR or ECM. The first advantage is that it estimates the relationships by levels. The model suggests that once the order of cointegration is recognised, the relationship can be estimated with the OLS standard. Secondly, it introduces the bound test that allows the mixture of $\mathrm{I}(0)$ and $\mathrm{I}(1)$ variables as regression. Thirdly, the approach involves a single equation setup, which makes it easier to implement and interpret. Finally, different variables may be assigned different lag lengths as they enter the model (Pesaran, Shin and Smith 2001).

\section{Analysis and Discussion}

\subsection{Construction of the Investor sentiment index}

This section illustrates the descriptive analysis of the unit root tests for each variable to be modelled by $\operatorname{ARDL}(\mathrm{p}, \mathrm{q})$. We examined the stationary of the residuals of the series with the augmented Dickey-Fuller (Dickey and Fuller, 1979) and Phillip-Perron (Phillips and Perron, 1988) tests. Both tests investigated the null hypothesis and confirmed that there is a unit root in the series. The unit root is tested as pure random walk, either with drift or with drift and time trend. 
The three models are thus the robustness tests in determining the stationarity of each series and the results are illustrated in Table 1.

Table 1: Descriptive statistics

\begin{tabular}{lllllll}
\hline & $\boldsymbol{L B L R}$ & $\boldsymbol{L C P I}$ & $\boldsymbol{L E E R}$ & LIPI & LM3 & LKLCI \\
\cline { 2 - 7 } $\begin{array}{l}\text { Observations } \\
\text { ADF: }\end{array}$ & 156 & 156 & 156 & 156 & 156 & 156 \\
with drift & -0.975 & $-3.246^{* *}$ & -1.804 & $-2.588^{*}$ & 1.5609 & -0.521 \\
with drift and trend & -1.899 & $-3.27^{*}$ & 1.821 & $4.905^{* * *}$ & -3.244 & $-3.162^{*}$ \\
without drift and trend & 0.701 & -0.601 & 0.572 & -0.691 & 10.73 & 1.037 \\
PP: & & & & & \\
with drift & -0.902 & $-3.582^{* * * *}$ & -2.125 & -2.097 & 1.428 & -0.521 \\
with drift and trend & -1.805 & $-3.6039^{* * *}$ & -2.143 & -5.081 & -3.244 & -3.162 \\
without drift and trend & 0.802 & $-0.558^{* * *}$ & 0.492 & 2.127 & 10.23 & 0.845 \\
\hline
\end{tabular}

The results from Table 1 show that LBLR, LEER and LM3 contain no evidence of unit root in all three models tested, and are, therefore, stationary in their series. In contrast, LCPI and LIPI contain unit roots. LKLCI seems to show the mild existence of unit root in its series. All three autoregressive models tested by $\mathrm{ADF}$ and PP gave significant results at $1 \%$ and $5 \%$ critical levels. As a remedy for the unit root problem, each series will be first or second-differenced prior to further parametric analyses. As $\operatorname{ARDL}(\mathrm{p}, \mathrm{q})$ does not require that all series have to be in the same level of integration, all variables may enter the same equation for further analysis.

The next stage is to construct a cleaner investor sentiment composite index that is free from the influence of macroeconomic variables, by regressing each of the proxies for the macroeconomic variables with the ARDL $(p, q)$ model. Similar to VAR, the selection of appropriate lags is determined by the AIC and SC criteria. As observed in previous analyses, SC is consistent and provides the least lag for the model. Table 2 shows the sequence of variables between the proxies and macroeconomic variables modelled by VAR with lags suggested by AIC and SC criteria.

Table 2: Lag Selection by AIC and SC criteria for ARDL Models

\begin{tabular}{lll}
\hline Variables sequence & AIC & SC \\
\hline$T U R N, B L R, C P I, E E R, I P I, M 3$ & $49.374(\operatorname{lag} 12)$ & $51.126(\operatorname{lag} 1)$ \\
NIPO, BLR, CPI, EER, IPI, M3 & $33.312(\operatorname{lag} 12)$ & $34.542(\operatorname{lag} 1)$ \\
RIPO, BLR, CPI, EER, IPI, M3 & $30.394(\operatorname{lag} 12)$ & $31.453(\operatorname{lag} 1)$ \\
ADV, BLR, CPI, EER, IPI, M3 & $29.933(\operatorname{lag} 12)$ & $31.274(\operatorname{lag} 1)$ \\
$C S I, B L R, C P I, E E R, I P I, M 3$ & $31.961(\operatorname{lag} 12)$ & $35.178(\operatorname{lag} 3)$ \\
\hline
\end{tabular}

For the CSI, BLR, CPI, EER, IPI, and M3 model, the SC criterion suggests a maximum of lag 3 . Therefore, we model each relationship as shown by equation 7 to equation 11 to represent the ARDL $(\mathrm{p}, \mathrm{q})$ model for TURN, NIPO, RIPO, $\mathrm{ADV}$ and CSI for a maximum lag of three months. The main purpose of running the variables through the ARDL $(p, q)$ model is to obtain a cleaner measure for each proxy to represent a cleaner representative of the investor sentiment composite index. The final ARDL $(p, q)$ models for each proxy and macroeconomic variable are as follows: 


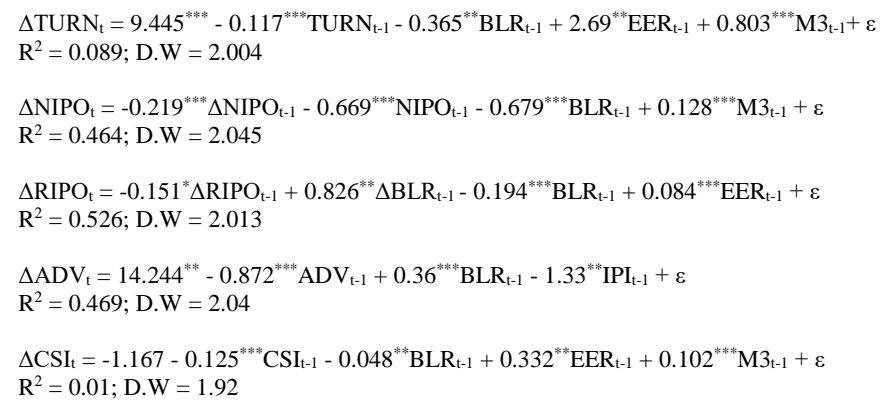

The results confirmed that the models are also free from autocorrelation (according to the Durbin Watson test) and heteroscedasticity (examined by the $\mathrm{ARCH}$ test). Then, the investor sentiment composite index is constructed from the residuals of all five proxy models. In constructing the investor sentiment composite index, we incorporated a current and a month lag of each cleaner proxy in order to construct the first-stage index (FSI). Next, to determine the correct timing for each proxy that correlates to the cleaner index movement, we computed the correlations between the proxy and the FSI. The results are shown in Table 3.

Table 3: Correlations between the Current and One-month Lag Proxies with FSI

\begin{tabular}{|c|c|c|c|c|c|}
\hline \multirow{3}{*}{ FSI } & $T U R N_{t}$ & $\operatorname{TURN}_{t-1}$ & $\mathrm{NIPO}_{t}$ & $N I P O_{t-1}$ & $\mathrm{RIPO}_{t}$ \\
\hline & 0.1 & 0.9 & -0.2 & -0.1 & 0.3 \\
\hline & $\operatorname{RIPO}_{t-1}$ & $A D V_{t}$ & $A D V_{t-I}$ & $\mathrm{CSI}_{t}$ & $C S I_{t-1}$ \\
\hline$F S I$ & 0.1 & 0.3 & 0.1 & 0.2 & 0.9 \\
\hline
\end{tabular}

From Table 3, each respective current proxy or one-month lag (whichever has a higher correlation with the first-stage index) is then selected for construction of the investor sentiment composite index. The final selection of proxies includes stock market turnover at lag one $\left(T U R N_{t-1}\right)$, number of IPOs at lag zero $\left(N I P O_{t}\right)$, initial returns of IPOs at lag zero $\left(R I P O_{t}\right)$, advancers and decliners ratio at lag zero $\left(A D V_{t}\right)$, and consumer sentiment index at lag one $\left(C S I_{t-1}\right)$. Next, proxies with respective timings are applied to the factor analysis with PCA extraction where each of the index components is standardised and coefficients are rescaled to a unit variance. The results from the factor analysis with PCA extraction are rotated using the Varimax procedure. Table 4 exhibits that the two principal components account for a cumulative $67 \%$ of the variance from the cleaner proxies.

Table 4: Total Variance Explained by Each Component

\begin{tabular}{lccc}
\hline Component & $\begin{array}{c}\text { Initial Eigenvalues } \\
\text { Total }\end{array}$ & Component & $\begin{array}{c}\text { Initial Eigenvalues } \\
\text { Total }\end{array}$ \\
\hline$P C 1$ & 2.153 & PC1 & 2.153 \\
$P C 2$ & 1.198 & PC2 & 1.198 \\
\hline
\end{tabular}

As suggested by Baker and Wurgler (2006; 2007; 2012), PC1, being the first principal component that accounts for the largest variation $\left(\sigma^{2}\right)$, is selected as the investor sentiment composite index. The factor loadings for PC1 and PC2 are shown in Table 5. The factor loadings justify the correlation of each proxy to each 
component, while factor weights represent how much each proxy contributes towards the constructed index. The factor weights are used to calculate the factor scores for the construction of the investor sentiment composite index, as shown by equation 12 .

Table 5: Factor Loadings for PC1 and PC2

\begin{tabular}{llllll}
\hline & $\boldsymbol{T U R N}_{\boldsymbol{t}-\boldsymbol{1}}$ & $\boldsymbol{N I P O}_{\boldsymbol{t}}$ & $\boldsymbol{R I P O}_{\boldsymbol{t}}$ & $\boldsymbol{A D V}_{\boldsymbol{t}}$ & $\boldsymbol{C S I}_{\boldsymbol{t} \boldsymbol{- 1}}$ \\
\hline 1 & 0.957 & -0.251 & 0.297 & 0.399 & 0.963 \\
2 & 0.135 & 0.796 & 0.704 & -0.191 & 0.113 \\
\hline
\end{tabular}

Another interesting fact to address is the correlation between each proxy and the investor sentiment composite index; as illustrated in the second column of Table 5. Focusing on the first principal component (PC1), one-month-lag CSI and TURN are highly correlated with the composite index determined by PC1. The investor sentiment composite index is then computed as weighted standardised proxies from Table 5 from 2000-2012. Therefore, the parsimonious equation for the sentiment index is:

$$
I S C I_{t}=0.44 T U R N_{t-1}-0.172 N^{2} P O_{t}+0.09 R I P O_{t}+0.2 A D V_{t}+0.45 C S I_{t-1}
$$

The investor sentiment composite index (ISCI) on monthly frequency is then plotted as per Figure 1.

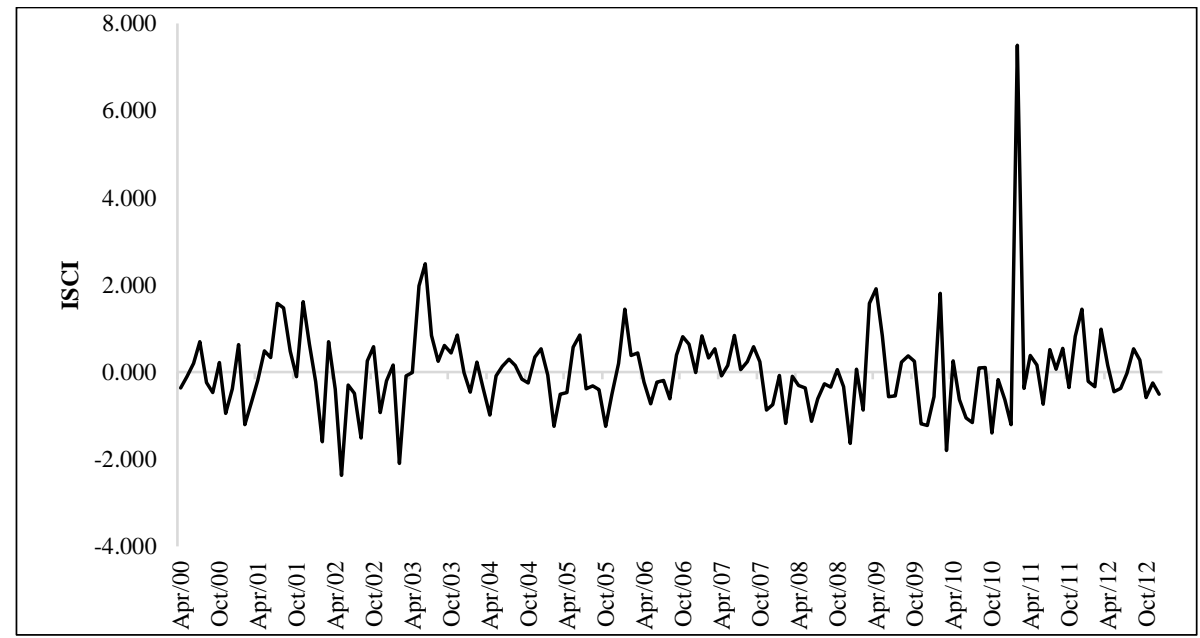

Figure 1: Investor Sentiment Movement, 2000-2012

Throughout 2000-2012, the ISCI seems to be consistent except for a couple of periods of apparent high positive sentiment observed in June 2003 and February 2011. These two periods were when the KLCI had continued its rally from 2010 due to the positive results of the listed companies' growth, which influenced the sentiment of investors towards the current outlook of the stock market. 


\subsection{Investor Sentiment and Stock Market Volatility}

The second objective of this study is to determine the explanatory power of investor sentiment on the volatility of the Malaysian stock market. Hence, we investigated the relationship between ISCI and the leading stock market indicator, the KLCI, its returns (RKLCI), and its volatility (VKLCI). The correlations between the variables are illustrated in Table 6 .

Table 6: Correlations between KLCI, ISCI, RKLCI, and VKLCI

\begin{tabular}{lllll}
\hline & $K L C I$ & $I S C I$ & $R K L C I$ & VKLCI \\
\cline { 2 - 5 } & 1 & & & \\
RKLCI & $0.224^{* *}$ & 1 & 1 & \\
$V K L C I$ & -0.03 & $-0.186^{* *}$ & -0.078 & 1 \\
\hline
\end{tabular}

Note: $* * *, * *$, and $*$ denote significance levels of $1 \%, 5 \%$, and $10 \%$ respectively.

The main interest of objective two is to observe the impact of investor sentiment on the volatility of the stock market. Thus, the results in Table 6 are discussed in relation to VKLCI. It is observed that KLCI and ISCI hold significant negative correlations with the volatility of KLCI. With any increases in KLCI, VKLCI decreases by $35.7 \%$. Being the cleaner index for investor sentiment, ISCI also declined by $17.1 \%$, which possibly means that whenever VKLCI moves positively, the investor sentiment becomes calmer. There are also strong correlations between ISCI and RKLCI; an increase in RKLCI results in a decrease in the investor sentiment composite index (ISCI). This partly justifies the construction of the cleaner investor sentiment composite index. Nevertheless, since correlations do not measure causality, they do not take into account the errors while computing the relationship; therefore, further tests are examined in detail in the following section. To examine the predictive power of the investor sentiment composite index, net macroeconomic fundamentals over the volatility of the Malaysian stock market, the following hypothesis is tested: The investor sentiment composite index has no significant causal relationship with the volatility of KLCI (VKLCI) for the whole period of study (2000-2012).

As all variables are stationary in nature, implying that there are no issues of spurious regression to test the relationship between investor sentiment indices and VKLCI, the simple VAR can be applied to model the relationships (Asteriou \& Hall, 2007). However, prior to modelling any distributive lag model including VAR, the optimal lags of the variables are determined. The optimal lag selection contributes to the accuracy of the forecasting model where it varies substantially for an alternative lag length (Hafer and Sheehan, 1989). Nevertheless, one has to be careful not to select a high order, since that tends to cause an increase in the mean square forecast errors of VAR; and under-fitting the lag length often generates auto-correlated errors (Lutkepohl, 1993). In line with the analysis discussed, the relationship between ISCI and VKLCI is modelled with VAR with different orders from lag 1 to 12 . The results computed by AIC and SC are illustrated in Table 7. 
Table 7: Lag Selection Criteria

\begin{tabular}{|c|c|c|c|c|c|c|}
\hline Lags & 1 & 2 & 3 & 4 & 5 & 6 \\
\hline AIC & -9.544 & -9.547 & -9.547 & -9.523 & -9.581 & -9.67 \\
\hline SC & -9.464 & -9.407 & -9.346 & -9.261 & -9.257 & -9.285 \\
\hline Lags & 7 & 8 & 9 & 10 & 11 & 12 \\
\hline AIC & -9.637 & -9.624 & -9.612 & -9.581 & -9.554 & -9.513 \\
\hline $\mathrm{SC}$ & -9.188 & -9.11 & -9.035 & -8.938 & -8.846 & -8.739 \\
\hline
\end{tabular}

Note: Figures in bold denote the lowest values of AIC and SC.

VAR models with lag 1 and lag 6 are selected by AIC and SC, respectively (Table 7). Using minimum AIC and SC procedures, the models are therefore fitted into a sample of 3 series: VKLCI, ISCI from 153 monthly time series. Nevertheless, VAR has a disadvantage. The obtained coefficients are difficult to interpret due to the lack of a theoretical background. In order to countervail potential criticism, it is important to estimate causality in the VAR models. As developed by Granger (1969), the causality test is defined as follows: a variable $Y_{t}$ is said to be Granger caused by $X_{t}$ if $Y_{t}$ can be predicted with greater accuracy by using past values of the $X_{t}$ variable, when all other variables remain unchanged.

$$
V K L C I_{t}=\alpha_{t}+\sum_{i=1}^{n} \beta_{1} I S C I_{t-j}+\sum_{i=1}^{n} \beta_{2} V K L C I_{t-j}+\varepsilon_{t}
$$

The null and alternated hypotheses are:

$\begin{array}{ll}\mathrm{H}_{0}: & \sum_{i=1}^{n} \beta_{i}=0 \text { or } I S C I_{t-j} \text { does not cause VKLCI } \\ \mathrm{H}_{1}: & \sum_{i=1}^{n} \beta_{i} \neq 0 \text { or } I S C I_{t-j} \text { does cause VKLCI }\end{array}$

The results for all three variables throughout the period of study according to each lag are presented in Table 8. The values with asterisk denote that the null hypothesis is rejected, thus supporting a causal relationship between the variables. Since one of the objectives of the study is to peruse the predictive power of investor sentiment to stock market volatility, this study justifies the selection of a VAR model for analysing the data.

Table 8: Granger Causality Relationship (2000-2012)

between VKLCI, ISCI and with Respective Lags

\begin{tabular}{llllllll}
\hline $\mathbf{Y}_{\mathbf{t}}$ & $\mathbf{X}_{\mathbf{t} \mathbf{j}}$ & $\boldsymbol{\chi}$ & Lags & $\mathbf{Y}_{\mathbf{t}}$ & $\mathbf{X}_{\mathbf{t} \mathbf{j}}$ & $\boldsymbol{\chi}$ & Lags \\
\hline VKLCI & ISCI & $2.63^{*}$ & 1 & VKLCI & ISCI & $15.24 * * *$ & 7 \\
VKLCI & ISCI & 3.46 & 2 & VKLCI & ISCI & $15.99 * *$ & 8 \\
VKLCI & ISCI & 3.75 & 3 & VKLCI & ISCI & $17.89^{* *}$ & 9 \\
VKLCI & ISCI & 4.79 & 4 & VKLCI & ISCI & $19.14 * *$ & 10 \\
VKLCI & ISCI & $12.22^{* *}$ & 5 & VKLCI & ISCI & $21.03 * * *$ & 11 \\
VKLCI & ISCI & $18.12^{* * *}$ & 6 & VKLCI & ISCI & $21.08^{* *}$ & 12 \\
\hline
\end{tabular}

Note: $* * *, * *$, and $*$ denote significance levels of $1 \%, 5 \%$, and $10 \%$, respectively. 
Table 8 presents the predictive power of ISCI over VKLCI in their respective lag until the maximum lag of twelve. In accordance with row 1 of Table 8, the hypothesis that there is no Granger causality between ISCI is rejected at the $10 \%$ level of significance. It is therefore observed that, at lag 1 , the investor sentiment significantly Granger-causes the volatility in KLCI. The effect disappears with the increase of lags until the re-appearance of the Granger causality in lag 5. It is apparent that the hypothesis is rejected at the 5\% level of significance for Granger causality of ISCI to VKLCI. The ISCI Granger-causes the volatility of KLCI from lag 5 until the maximum lag of 12 . Therefore, there is evidence that the predictability of the cleaner index of investor sentiment over the stock market volatility is significant in longer horizons. These results are consistent with what is reported by Baker and Cliff (2005). Using direct surveys as a proxy for investor sentiment, they found that it could predict market returns over a period of 1 to 3 years horizon. Although applying different proxies and methodology, the findings from this paper conclude with similar suggestions.

As tested in the hypothesis, the investor sentiment composite index seems to prove its effectiveness as an appropriate index to represent investor sentiment specifically in the Malaysian stock market. The investor sentiment composite index manages to predict the volatility of the stock market as early as five to twelve months for the entire period of 13 years of the study, which is consistent with Brown and Cliff (2005). A possible theoretical explanation was posited by DeLong, Shleifer, Summers, and Waldmann (1990), where noise traders believed that they have special information about the future price of risky assets. They received these pseudo-signals from technical analysts, stockbrokers, or from economic consultants, and reacted accordingly. By and large, in the absence of fundamental risks, arbitrageurs have limited opportunities due to the difficulty in liquidating their investment in short horizons, thus creating larger divergences from their fundamental values, which yields higher returns for noise traders. These divergences thus explain the prolonged higher returns and volatility of stock prices that still exists in the longer horizon.

\section{Conclusion}

Theoretically, it is established in the modern portfolio theory that stock markets are claimed to be efficient when no factor can explain or predict their movement. In most traditional finance theories, the contribution of investor sentiment has been rejected. Nevertheless, given the results of this study, it is apparent that the non-fundamental factor - investor sentiment - systematically explains the movement of the Kuala Lumpur Composite Index, and, therefore, may reject the notion that the Malaysian stock market is efficient. Investor sentiment has also spurred much interest in an attempt to explain the existing asset pricing theories. With enlightenment from the findings of this study, investors are likely to be aware of their financial surroundings, being equipped with strategies prior to available announcements. Information on consumer sentiment index is crucial as investors are likely to be able to carry out prudent measures to avoid entering the 
stock market during high volatility, or to take advantage of fluctuations in price and make abnormal returns resulting from price spread. As the findings from this study reveal, investor sentiment plays an important role in predicting the movement of the KLCI, especially on a longer prediction of five months and beyond; investors may consider investor sentiment just as important as other technical analysis' indicators in formulating their investment strategies. Investor sentiment may be adopted as the contrarian indicator, where traders will view upon and apply an opposite position with the hope of making abnormal returns from the strategy.

From a broader perspective, the findings from this study also have significant implications for policymakers and regulators, such as the Malaysian stock market exchange, Bursa Malaysia. The findings from this study suggest that in order to form new policies, Bursa Malaysia should focus on the effect of investors' sentiment on stock market volatility. This is a crucial period when effective approaches have to be applied in conjunction with appropriate tools to eradicate any irrational reactions from stock market sentiments. Additionally, in expectation of the irrational movement of the stock prices, an early intervention from policymakers can also be carried out.

\section{References}

Aggarwal, R., Leal, R., \& Hernandez, L. (1993). The Aftermarket Performance of Initial Public Offerings in Latin America. The Journal of the Financial Management Association, 22(1), 42-53.

Ali, N., Md Nassir, A., Hassan, T., \& Zainal Abidin, S. (2009). Does Bursa Malaysia Overreact? International Research Journal of Finance and Economics, (34), 175-193.

Ali, N., Md Nassir, A., Hassan, T., \& Zainal Abidin, S. (2010). Short Run Stock Overreaction: Evidence from Bursa Malaysia. International Journal of Economics and Management, 4(2), 319-333.

Angabini, A., \& Wasiuzzaman, S. (2011). GARCH models and financial crisis a study of the malaysian stock market. The International Journal of Applied Economics and Finance, 5(3), 226-236.

Asteriou, D., \& Hall, S. G. (2007). Applied Econometrics: A Modern Approach Using Eviews and Microfit. Palgrave Macmillan.

Baker, M. P., \& Stein, J. (2004). Market liquidity as a sentiment indicator. Journal of Financial Markets, 7(3), 271-299.

Baker, M. P., \& Wurgler, J. (2006). Investor Sentiment and the Cross-Section of Stock Returns. The Journal of Finance, 61(4), 1645-1680.

Baker, M. P., Wurgler, J., \& Yuan, Y. (2012). Global, Local, and Contagious Investor Sentiment. Journal of Financial Economics, 104(2), 272-287.

Baker, M., \& Wurgler, J. (2007). Investor Sentiment in the Stock Market. Journal of Economic Perspectives, 21(2), 129-151.

Beltratti, A., \& Morana, C. (2002). Breaks and Persistency: Macroeconomic Causes of Stock Market Volatility. Journal of Econometrics, 131(1-2), 1-66. 
Brailsford, T. J., \& Faff, R. W. (1996). An evaluation of volatility forecasting techniques. Journal of Banking \& Finance, 20(3), 419-438.

Brown, G. W. (1999). Volatility, Noise Traders. Financial Analysts Journal, 55(2), 82-90.

Brown, G. W., \& Cliff, M. T. (2004). Investor sentiment and the near-term stock market. Journal of Empirical Finance, 11(1), 1-27.

Brown, G. W., \& Cliff, M. T. (2005). Investor Sentiment and Asset Valuation. Journal of Business, 78(2), 405-440.

Chan, W., Frankel, R., \& Kothari, S. (2004). Testing behavioral finance theories using trends and consistency in financial performance. Journal of Accounting and Economics, 38, 3-50.

DeLong, J. B., Shleifer, A., Summers, L. H., \& Waldmann, R. J. (1990). Positive Feedback Investment Strategies and Destabilizing Rational Speculation. The Journal of Finance, 45(2), 379-395.

Derrien, F. (2005). IPO Pricing in "Hot" Market Conditions : Who Leaves Money on the Table? The Journal of Finance, 60(1), 487-521.

Dickey, D. A., \& Fuller, W. A. (1979). Distribution of the Estimators for Autoregressive Time Series With a Unit Root. Journal of American Statistical Association, 74(366), 427-431.

Diebold, F. X., \& Yilmaz, K. (2008). Macroeconomic Volatility and Stock Market Volatility, Worldwide (No. E0, G1). Cambridge.

Dorn, D. (2009). Does Sentiment Drive the Retail Demand for IPOs? Journal of Financial and Quantitative Analysis, 44(01), 85.

Engle, R. F., Ghysels, E., \& Sohn, B. (2013). Stock Market Volatility and Macroeconomic Fundamentals. Review of Economics and Statistics, 95(3), 776-797.

French, K. R., Schwert, G. W., \& Stambaugh, R. F. (1987). Expected stock returns and volatility. Journal of Financial Economics, 19, 3-29.

Harvey, C. R. (1989). Forecasts of economic growth from the bond and stock markets. Financial Analysts Journal Journal, (September - October), 38-45.

Kim, K., \& Nofsinger, J. (2008). Behavioral finance in Asia. Pacific-Basin Finance Journal, 16(1-2), 1-7.

Kraft, J., \& Kraft, A. (1977). Determinants of Common Stock Prices: A Time Series Analysis. The Journal of Finance, 32(2), 417-425.

Lee, C. M. C., Shleifer, A., \& Thaler, R. H. (1991). Investor Sentiment and Closed-End Fund Puzzle. The Journal of Finance, 46(1), 75-109.

Lee, W. Y., Jiang, C. X., \& Indro, D. C. (2002). Stock market volatility, excess returns, and the role of investor sentiment. Journal of Banking and Finance, 26(12), 2277-2299.

Lowry, M. (2003). Why does IPO volume fluctuate so much? Journal of Financial Economics, 67, 3-40.

Neal, R., \& Wheatley, S. M. (1998). Do measures of investor sentiment predict returns. Journal of Financial and Quantitative Analysis, 33(4),523-547.

Pesaran, H., \& Shin, Y. (1997). An Autoregressive Distributed Lag Modelling Approach to Cointegration Analysis. In Econometrics and Economic Theory 
in the 20th Century: The Ragnar Frisch Centennial Symposium, Strom S. Cambridge: Cambridge University Press.

Pesaran, H., Shin, Y., \& Smith, R. (2001). Bounds testing approaches to the analysis of level relationships. Journal of Applied Econometrics, 16(3), 289326.

Phillips, P. C. ., \& Perron, P. (1988). Testing for a Unit Root in Time Series Regression. Biometrika, 75, 335-346.

Rahman, A. A., Sidek, N. Z. M., \& Tafri, F. H. (2009). Macroeconomic determinants of Malaysian stock market. African Journal of Business Management, 3(3), 95-106.

Ritter, jay R., \& Welch, I. (2002). A Review of IPO Activity, Pricing and Allocations. The Journal of Finance, 57(4), 1795-1828.

Shiller, R. J. (1987). The Volatility of Stock Market Prices. Science, New Series, 235(4784), 33-37.

Shiller, R. J. (1989). Market Volatility. Cambridge: MIT Press, Cambridge, MA.

Verma, R., \& Verma, P. (2007). Noise trading and stock market volatility. Journal of Multinational Financial Management, 17(3), 231-243.

Yung, C., Colak, G., \& Wang, W. (2008). Cycles in the IPO market. Journal of Financial Economics, 89(1), 192-208. 